\title{
Antiallergic Effect of Hizikia fusiformis in an Ovalbumin-Induced Allergic Rhinitis Mouse Model
}

\author{
Yu-Lian Zhang ${ }^{1}$ (D) $\cdot$ Hyun-Jae Shin ${ }^{2} \cdot$ Jung-Heon Lee $^{2} \cdot$ Jieun Lee $^{3}$ (D) \\ ${ }^{1}$ Center of Morphological Experiment, Medical College of Yanbian University, Yanji, China; \\ ${ }^{2}$ Department of Biochemical and Polymer Engineering, Chosun University, Gwangju; \\ ${ }^{3}$ Department of Otorhinolaryngology-Head and Neck Surgery, Chosun University College of Medicine, Gwangju, Korea
}

Objectives. The extract of Hizikia fusiformis is known to exhibit anticancer, antiatopic and antioxidant activities. We aimed to investigate the extract of $H$. fusiformis on allergic rhinitis inflammation in a mouse model.

Methods. The 4-week-old BALB/c mice were randomly assigned into four groups: group A, control group (n=9); group B, allergic rhinitis group $(\mathrm{n}=10)$; group $\mathrm{C}(\mathrm{n}=10)$ received $300 \mathrm{mg} / \mathrm{kg}$ of $H$. fusiformis during nasal challenging period; group D ( $\mathrm{n}=10)$ received $600 \mathrm{mg} / \mathrm{kg}$ of $H$. fusiformis during general sensitization period and $300 \mathrm{mg} / \mathrm{kg}$ of $H$. fusiformis during nasal challenging period. Allergic inflammation was made with ovalbumin (OVA) and alum then challenged intranasally with OVA. H. fusiformis was intraperitoneally administered 3 hours before the OVA administration. Allergic symptom score and the levels of immunoglobulin $\mathrm{G}_{1}\left(\mathrm{IgG}_{1}\right), \mathrm{IgG}_{2 \mathrm{a}}$, OVA-specific $\operatorname{IgE}$ antibodies, levels of cytokines in the nasal mucosa and in spleen cell culture supernatant, such as tumor necrosis factor alpha (TNF- $\alpha$ ), interleukin 4 (IL-4), IL-5, IL-13, and IL-10 were assessed. The percentage of regulatory T cell was analyzed by flow cytometry. Eosinophilic infiltration and goblet cell hyperplasia were also evaluated.

Results. H. fusiformis administered groups $\mathrm{C}$ and $\mathrm{D}$ showed significant inhibitory effects on nasal symptoms, IL-13 mRNA expression and eosinophil infiltration/goblet cell hyperplasia in the nasal tissue; OVA-specific IgE production in serum $(P<0.05)$. In group $\mathrm{D}, H$. fusiformis treatment downregulated IL-4, IL-5, IL-13, TNF- $\alpha$, and IL-10 cytokine expression in splenocyte culture as well as significantly decreased $\operatorname{IgG}_{2 a}, I_{g G}$ levels in serum compared with group $B$ $(P<0.05)$. However, the expressions of IL-5, interferon- $\gamma$ and forkhead box P3 mRNA did not change in groups $\mathrm{C}$ and $\mathrm{D}$.

Conclusion. H. fusiformis could induce antiallergic inflammation by suppressing the T-helper type 2 cytokine production (IL-13) locally and systemically, OVA-specific IgE formation, goblet cell hyperplasia, and eosinophilic infiltration in a mouse model of allergic rhinitis. Thus, $H$. fusiformis could be considered as a potential therapeutic agent in treating allergic rhinitis.

Keywords. Allergic Rhinitis; Th2 Cells; Inflammation; Mice

\section{INTRODUCTION}

- Received January 11, 2019

Revised February 14, 2019

Accepted February 14, 2019

- Corresponding author: Jieun Lee

Department of Otorhinolaryngology-Head and Neck Surgery,

Chosun University College of Medicine, 309 Pilmun-daero, Dong-gu,

Gwangju 61452, Korea

Tel: +82-62-230-3206, Fax: +82-62-225-2702

E-mail: jeviolin@hanmail.net

\begin{abstract}
Allergic rhinitis is characterized by sneezing, rhinorrhea, nasal obstruction, and itching of nose. The prevalence of allergic rhinitis is increasing worldwide. Allergic diseases, including allergic rhinitis, are mediated by immunoglobulin $\mathrm{E}(\mathrm{IgE})$ and characterized with T-helper type 2 (Th2)-mediated allergic inflammation. Thus, interleukin 4 (IL-4), IL-5, and IL-13 are important cytokines in allergic response.
\end{abstract}

Copyright @ 2019 by Korean Society of Otorhinolaryngology-Head and Neck Surgery.

This is an open-access article distributed under the terms of the Creative Commons Attribution Non-Commercial License (http://creativecommons.org/licenses/by-nc/4.0)

which permits unrestricted non-commercial use, distribution, and reproduction in any medium, provided the original work is properly cited. 
Hizikia fusiformis is a sea vegetable growing on rocky coastlines around temperate seaside areas of Korea, Japan, and China. $H$. fusiformis is a rich source of dietary fibers and essential minerals such as calcium, iron, and magnesium. Thus, $H$. fusiformis forms an important part of diet in Japan. Several studies have reported that the extract of $H$. fusiformis exerts immunomodulatory functions, anticancer effects, anti-inflammatory and antioxidant activities [1-8]. A recent study demonstrated the antiatopic effect of this extract using an 2,4-dinitrochlorobenzenetreated BALB/c mice model of atopic dermatitis. $H$. fusiformis had been shown to have antiatopic effect by effectively inhibiting $\mathrm{T}$ cell activation by inhibiting dephosphorylation of nuclear factor of activated $\mathrm{T}$ cells and thus eliminating Th1 and Th2-type cytokines IL-2, IL-4, and interferon $\gamma(\mathrm{IFN}-\gamma)$ [9]. These properties of $H$. fusiformis may be useful for its application for the treatment of allergic diseases.

Very few studies have evaluated the antiallergic effects of $H$. fusiformis associated with Th1,Th2 and regulatory T cells (Tregs). In the present study, we evaluated the antiallergic effect of $H$. fusiformis in a mouse model of allergic rhinitis using ovalbumin (OVA; Sigma, St. Louis, MO, USA) and elucidated the underlying mechanism.

\section{MATERIALS AND METHODS}

\section{Experimental animals}

Four-week-old female BALB/c mice were obtained from Orient Bio (Seongnam, Korea) and used in this study. This experiment was performed according to the guidelines of the Ethics of the Institutional Animal Care and Use Committee (No. CIACUC2018-S0003).

\section{Preparation of $H$. fusiformis extract}

$H$. fusiformis was subjected to extraction and purification in the Department of Biochemical and Polymer Engineering, Chosun University. Freeze-dried $H$. fusiformis was ground in a mixer and $2 \mathrm{~g}$ of the powder was digested and extracted at $50^{\circ} \mathrm{C}$ with 100 $\mu \mathrm{L}$ of viscozyme (in $100 \mathrm{~mL}$ of $0.1 \mathrm{M}$ sodium acetate buffer solution $\mathrm{pH} 4.5)$ for 6 hours in a shaking incubator (200 rpm). After digestion, viscozyme was deactivated at $100^{\circ} \mathrm{C}$ for $15 \mathrm{~min}$ utes and the supernatant was harvested with centrifugation

\section{H I G H L I G G H T S}

- Hizikia fusiformis reduced allergic symptom scores, infiltration of eosinophil, and hyperplasia of goblet cell.

- H. fusiformis reduced ovalbumin-specific immunoglobulin E formation.

- H. fusiformis reduced interleukin 13 production locally and systemically in allergic rhinitis mouse model.
$(10,000 \times g$ for 10 minutes). The supernatant was concentrated in a rotary evaporator, and the extract powder was prepared using a lyophilizer. The viscozyme fraction of $H$. fusiformis was used in all experiments.

\section{Experimental protocols}

Mice were randomized into four groups and each group comprised nine or ten mice. Group A ( $\mathrm{n}=9)$ was the negative control group, while group $B(n=10)$ was the positive control group. Group C $(\mathrm{n}=10)$ received $H$. fusiformis extract during the nasal challenge period, while group $\mathrm{D}(\mathrm{n}=10)$ received $H$. fusiformis during sensitization and nasal challenge period. Protocol for OVA sensitization and challenge for the development of allergic rhinitis mouse model is summarized in Fig. 1. Briefly, all mice, except from the negative control group, were immunized with an intraperitoneal injection of 25- $\mu$ g OVA absorbed on $2 \mathrm{mg}$ of aluminum hydroxide on days 0,7 , and 14 . Mice from group D were intraperitoneally treated with $600 \mathrm{mg} / \mathrm{kg}$ of $H$. fusiformis extract dissolved in $200 \mu \mathrm{L}$ of sterile water about 3 hours before OVA sensitization. After sensitization, these mice were intranasally challenged with $100-\mu \mathrm{g}$ OVA in $20 \mu \mathrm{L}$ of phosphate-buffered saline (PBS) for 7 consecutive days. Mice from group C and group D were intraperitoneally treated with $300 \mathrm{mg} / \mathrm{kg}$ of H. fusiformis about 3 hours before nasal challenge with OVA (on days 21-25). The group A were treated with PBS via the same route on the same schedule. The dose of $H$. fusiformis was determined arbitrarily within safe range based on the previous study [10].

\section{Nasal symptom scores}

After the final OVA challenge on day 27, the number of sneezing and nasal rubbing during 10 minutes was recorded and compared between the experimental groups by two observers blinded to the experimental conditions.

\section{Histologic assessment}

Mice were sacrificed 24 hours after the last OVA challenge. The heads were fixed in $10 \%$ neural buffered formaldehyde solution for 1 day, washed in running water for 4 hours, decalcified for 1 day using Calci-Clear Rapid (National Diagnostics, Atlanta, GA, USA) at room temperature, dehydrated, and embedded in paraffin blocks. These blocks were cut into $4-\mu \mathrm{m}$-thick coronal sections and stained with Sirius red to evaluate the number of eosinophils in the subepithelial connective tissue of the nasal mucosa. The other slide was stained with Periodic acid-Schiff (PAS) stain to evaluate the goblet cell hyperplasia in the epithelial layer. The average number of eosinophil/goblet cell was counted in four high-power field areas around the nasal septum $(\times 400 \mathrm{mag}-$ nification). The individuals who counted the cells were blinded to the experimental conditions. 


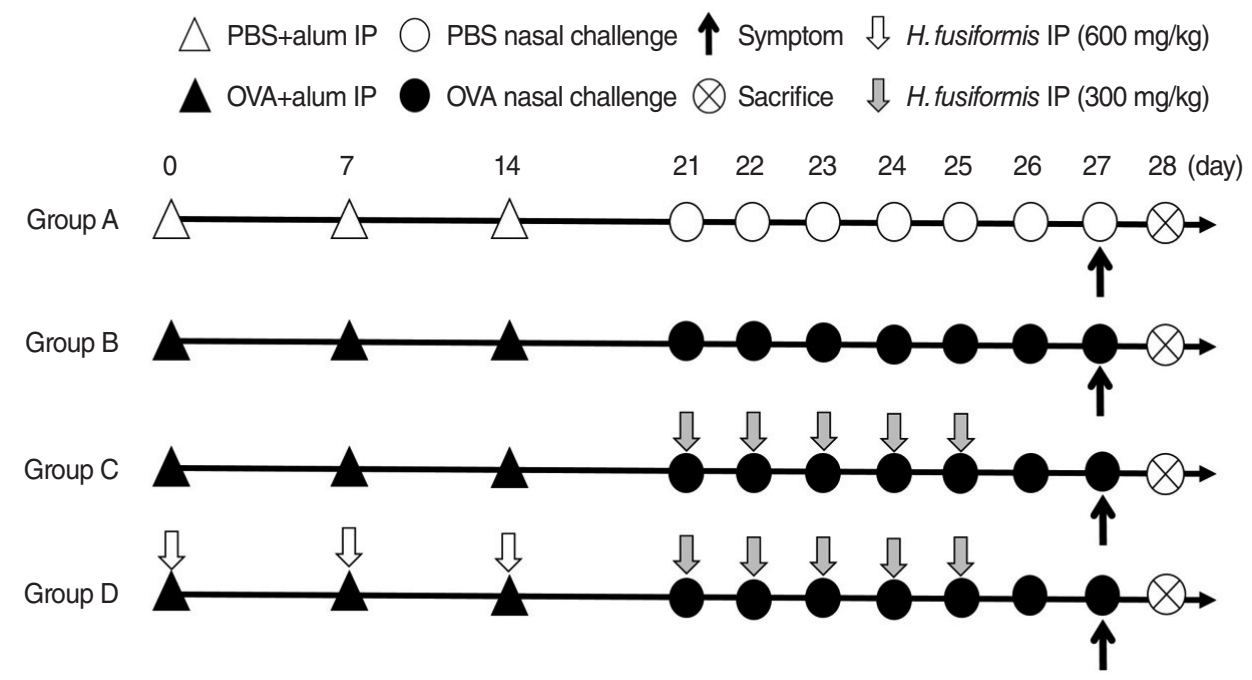

Fig. 1. Schematic representation of the experimental protocol. (General sensitization) BALB/c mice were sensitized with $25 \mu \mathrm{g}$ of ovalbumin (OVA) and $2 \mathrm{mg}$ of aluminum hydroxide gel on days 0,7 , and 14. (Local sensitization) all mice except for group A received intranasal challenge with OVA from day 21 to 27. In group C, mice received Hizikia fusiformis (H. fusiformis, $300 \mathrm{mg} / \mathrm{kg}$ ) 3 hours before intranasal OVA challenge from day 21 to 25. In group D, mice received $H$. fusiformis (600 mg/kg) 3 hours before intraperitoneal OVA administration on days 0 , 7 , and 14 and $\mathrm{H}$. fusiformis (300 mg/kg) 3 hours before intranasal OVA challenge. PBS, phosphate-buffered saline; IP, intraperitoneal injection.

Measurement of serum levels of OVA-specific $\lg E, \lg _{1}$, and $\lg G_{2 a}$

Blood samples were collected and the serum was separated by centrifuge. The levels of OVA-specific IgE antibodies (Abs) in the serum were evaluated using an enzyme-linked immunosorbent assay (ELISA), as previously described [11]. Briefly, serum samples were loaded in the wells of a 96-well plate coated with $10 \mu \mathrm{g} / \mathrm{mL}$ of OVA, and immunoglobulins were detected with biotin-conjugated anti-mouse IgE Ab, $\operatorname{IgG}_{1}$, and $\operatorname{IgG}_{2 a}$ (BD Biosciences, San Jose, CA, USA), respectively. The response was developed with a 3,3'5,5'-tetramethylbenzidine solution, followed by treatment with $2 \mathrm{~N}$ sulfuric acid to terminate the reaction. The absorbance was checked at $450 \mathrm{~nm}$ with a microplate reader (Epoch; BioTek, Winooski, VT, USA).

Real-time polymerase chain reaction for IL-5, IL-10, IFN- $\gamma$, and FOXP3 in the nasal mucosa

The nasal mucosa samples from the same group were mixed together since the amount of tissue was too small in each mouse. Total RNA was extracted from the nasal mucosa using TRIzol reagent (Invitrogen, Carlsbad, CA, USA). Complementary DNA was made with amfiRivert cDNA synthesis platinum master mix (GenDEPOT, Barker, TX, USA). The cDNAs corresponding to IL-5, IL-13, IFN- $\gamma$, forkhead box P3 (FOXP3), and glyceraldehyde-3-phosphate dehydrogenase (GAPDH) were amplified using ABI 7500 fast real-time PCR system (Applied Biosystems, Foster City, CA, USA). The primers used are presented in Table 1. The results were normalized to GAPDH expression level and expressed as fold change compared to the negative control group.
Table 1. Primers used in the experiments

\begin{tabular}{lll}
\hline Primer & & \multicolumn{1}{c}{ Sequence } \\
\hline IL-5 & Forward & 5'-GACGAGGCAGTTCCTGGAT-3' \\
& Reverse & 5'-GCATATGGTATCCCTTGCAT-3' \\
IL-13 & Forward & 5'-CCTCTGACCCTTAAGGAGCTTAT-3' \\
& Reverse & 5'-CGTTGCACAGGGGAGTCT-3' \\
IFN- $\gamma$ & Forward & 5'-AGAGCCAGATTATCTCTITCTACCTCAG-3' \\
& Reverse & 5'-CCTITCGCCTTGCTGTTG-3' \\
FOXP3 & Forward & 5'-GAAAGCGGATACCAAATGA-3' \\
& Reverse & 5'-CTGTGAGGACTACCGAGCC-3' \\
GAPDH & Forward & 5'-GCACAGTCAAGGCCGAGAAT-3' \\
& Reverse & 5'-GCCTTCTCCATGGTGGTGAA-3' \\
\hline
\end{tabular}

Measurement of cytokines (IL-4, IL-5, IL-13, TNF- $\alpha$, and IL-10) levels in splenocyte culture

A total of $5 \times 10^{6}$ single spleen cells were cultured in triplicates and incubated in Roswell Park Memorial Institute-1640 medium supplemented with $10 \%$ fetal bovine serum and 100 units $/ \mathrm{mL}$ penicillin and $100 \mu \mathrm{g} / \mathrm{mL}$ streptomycin (Gibco, Grand Island, NY, USA). After stimulation with OVA for 72 hours, the supernatant was collected and used for analysis. The levels of IL-4, IL-5, IL-10, IL-13, and tumor necrosis factor $\alpha$ (TNF- $\alpha$ ) were analyzed with ELISA kits (R\&D Systems, Minneapolis, MN, USA).

\section{Flow cytometry analysis}

Aliquots of $10^{6}$ splenic mononuclear cells were prepared and incubated with anti-mouse CD16/CD32 Ab for blocking nonspecific Fc-mediated interaction for 20 minutes on ice, followed by incubation with fluorescein isothiocyanate-conjugated antimouse $\mathrm{CD} 4 \mathrm{Ab}$ and anti-allophycocyanin-CD25 Ab (eBiosci- 
ence, San Diego, CA, USA) for 30 minutes on ice. After surface staining, the cells were incubated with fixation/permeabilization working solution overnight at $4^{\circ} \mathrm{C}$ and subsequently stained with phycoerythrin-Cy5-conjugated anti-mouse FOXP3 ${ }^{+}$(eBioscience) for 1 hour. $\mathrm{CD} 4^{+} \mathrm{CD} 25^{+} \mathrm{FOXP} 3^{+} \mathrm{T}$ cells were analyzed with BD FACSCalibur flow cytometer (BD Biosciences, San Jose, CA, USA).

\section{Statistical analysis}

All measured parameters are expressed as mean \pm standard deviation. Differences among the groups were analyzed with the Mann-Whitney $U$-test. All statistical analyses were conducted using IBM SPSS ver. 20.0 (IBM SPSS Corp., Chicago, IL, USA). A value of $P<0.05$ is used as the cutoff for significance.

\section{RESULTS}

Reduced allergic symptoms and serum OVA-specific lgE, $\lg G_{1}$, and $\lg G_{2 a} A b s$ after $H$. fusiformis treatment

To evaluate the effect of $H$. fusiformis extract on allergic nasal symptoms, the number of sneezes and rubbing movements were counted 5 minutes after the last nasal challenge for 10 minutes. The allergic symptom score significantly increased in the mice from group B as compared with those from the negative control group A. The score was significantly decreased for the mice from groups $\mathrm{C}$ and $\mathrm{D}$, compared with positive control group $\mathrm{B}(P<0.05)$ (Fig. 2A). Moreover, mice from group B showed significantly higher levels of OVA-specific IgE $\mathrm{Ab}$ than those from groups $\mathrm{C}$ and D. The levels of OVA-specific IgE Ab were significantly lower in mice from group D than from group C (Fig. 2B). This result suggests that $H$. fusiformis extract protected the mice from OVA sensitization. Analysis of $\operatorname{IgG}_{1}$ and $\operatorname{IgG}_{2 a} \mathrm{Ab}$ levels revealed that the expression of these Abs decreased in the mice from groups $\mathrm{C}$ and D (Fig. 2C, D). To evaluate the relative significant impact of $H$. fusiformis treatment on Th 2 or Th1 inflammation, $\operatorname{IgG}_{1} / \mathrm{G}_{2 a}$ ratio was calculated. The value of the ratio was lower in samples from group D than from group C (data not shown).

\section{Systemic effects of $H$. fusiformis evident from cytokine production and flow cytometric analysis of $\mathrm{CD}^{+}{ }^{+} \mathrm{CD} 25^{+} \mathrm{FOXP3}^{+} \mathrm{T}$ cells from splenocytes}

In terms of systemic effect of $H$. fusiformis, the levels of IL-4, IL-5, IL-13, IL-10, and TNF- $\alpha$ were significantly elevated in the culture supernatant of spleen cells from group B, while these levels significantly decreased following administration of $H$. fusiformis extract in group D (Fig. 3A). Evaluation of the systemic effects of $H$. fusiformis showed that the basal concentration of IL-10 was higher unlike the levels of other cytokines. The basal concentration of IL-10 in splenocyte culture supernatants with-
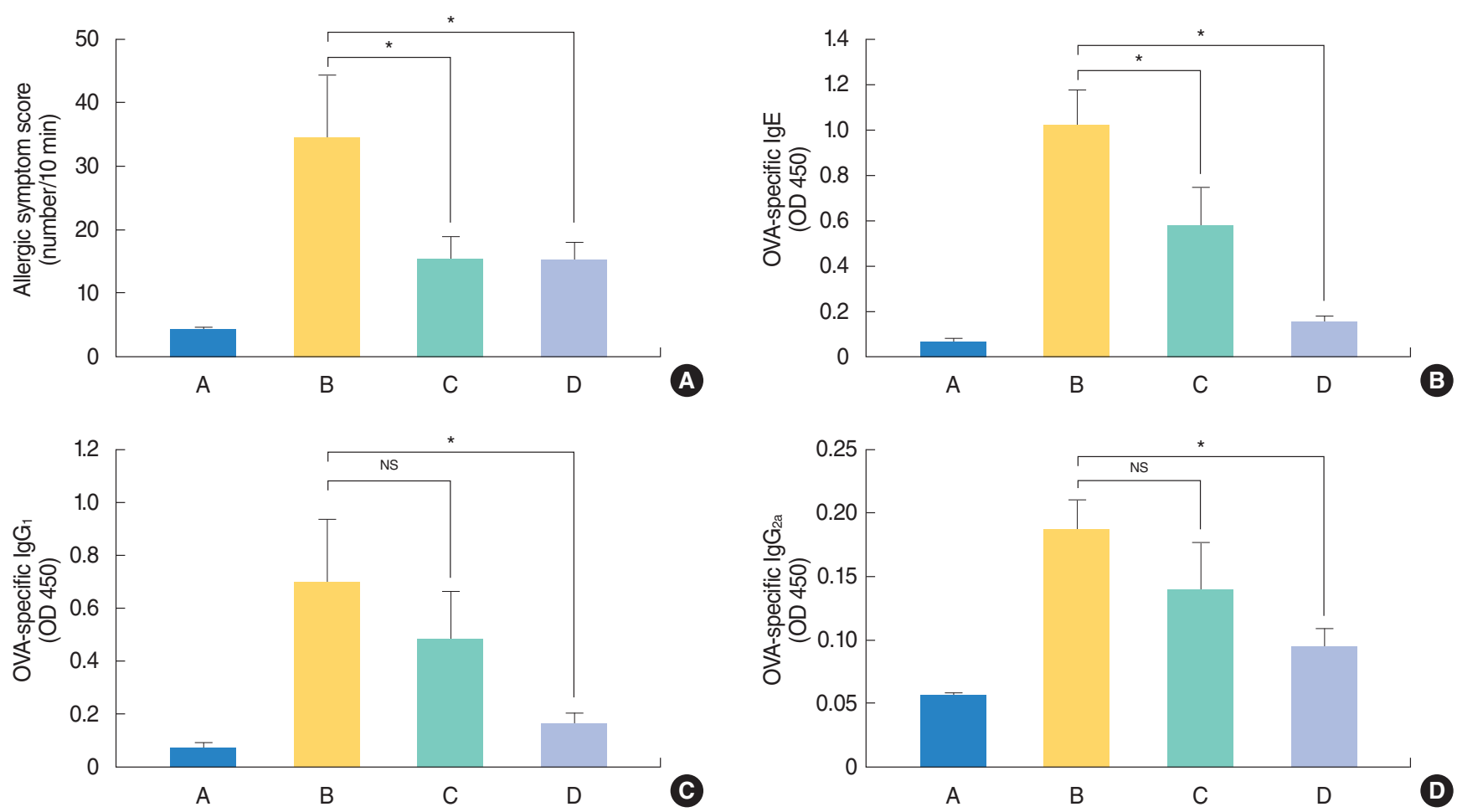

Fig. 2. Effect of Hizikia fusiformis on levels of (A) allergic symptom score and (B-D) serum ovalbumin (OVA)-specific immunoglobulins in each group. Administration of $H$. fusiformis suppressed allergic symptoms including rubbing and sneezing, and serum immunoglobulin $E$ (lgE) (B), $\lg _{1}(\mathrm{C})$, and $\lg \mathrm{G}_{2 \mathrm{a}}(\mathrm{D})$ levels. A, control group; $\mathrm{B}$, allergic rhinitis group; C, H. fusiformis treatment group during nasal challenging period; $\mathrm{D}$, H. fusiformis treatment group during general sensitization and nasal challenging period; NS, not significant. ${ }^{*} P<0.05$. 

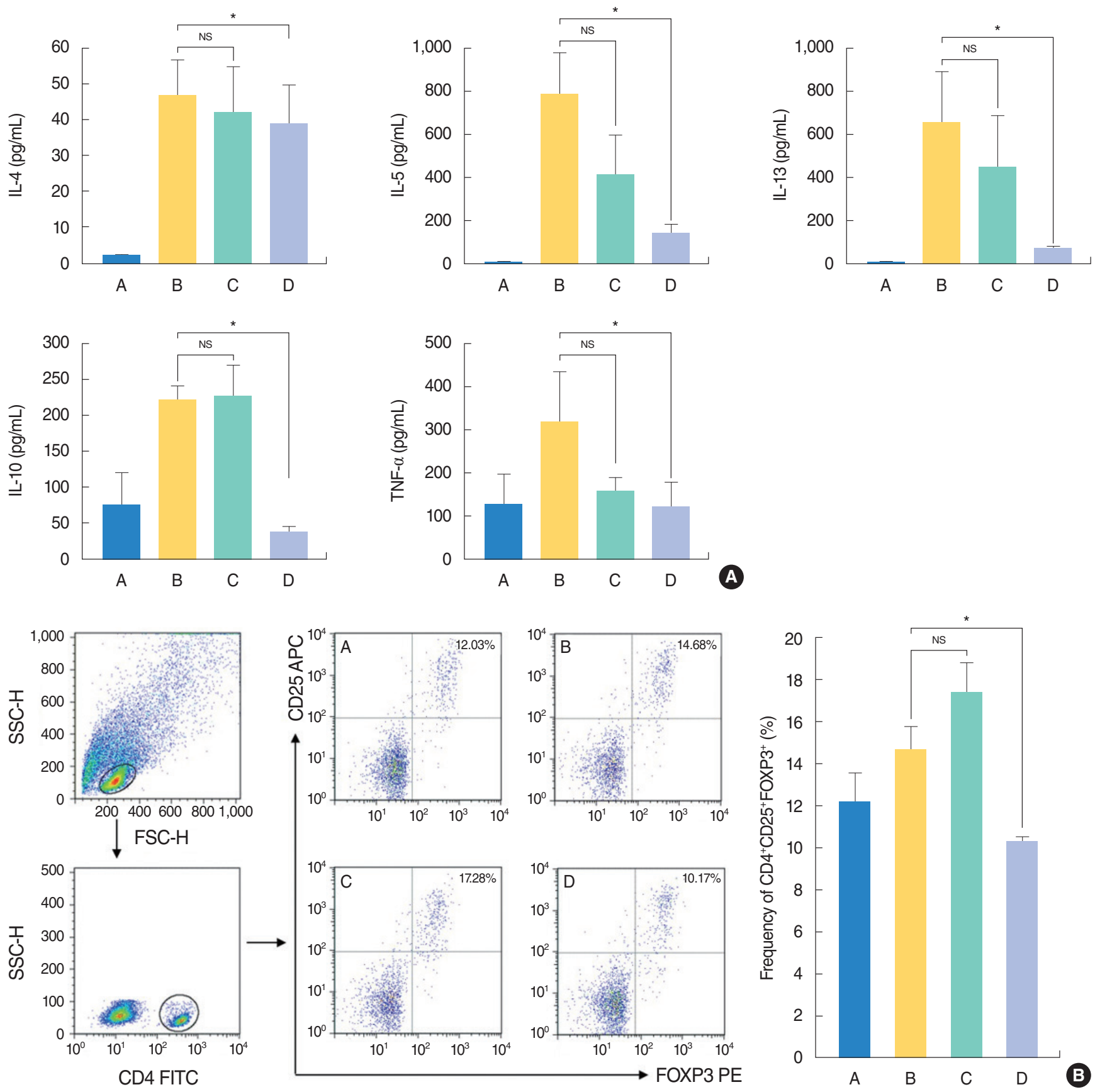

Fig. 3. Effect of Hizikia fusiformis on the (A) production of Th1/Th2 cytokines and (B) induction of regulatory T cell subgroups in spleen cell culture. (A) In spleen cell culture supernatant, interleukin 4 (IL-4), IL-5, IL-13, IL-10 and tumor necrosis factor alpha (TNF- $\alpha$ ) concentrations were decreased significantly in group D compared with the group B. (B) The frequency of CD4 ${ }^{+} \mathrm{CD} 25^{+} \mathrm{FOXP} 3^{+}$was decreased significantly in group $\mathrm{D}$ when the splenocyte cultured to OVA compared to the positive control group B. However, others did not show significant change after treatment. Experiments were performed three times. A, control group; B, allergic rhinitis group; C, H. fusiformis treatment group during nasal challenging period; D, H. fusiformis treatment group during general sensitization and nasal challenging period; NS, not significant; SSC-H, side scatter height; FSC-H, forward scatter height; FITC, fluorescein isothiocyanate; APC, allophycocyanine; PE, phycoerythrin. ${ }^{\star} P<0.05$.

out OVA stimulation was higher in group $\mathrm{C}$ and group $\mathrm{D}$ samples (up to $100 \mathrm{pg} / \mathrm{mL}$ ). After OVA stimulation, the level of IL-10 increased in groups B and C but remained constant in group D (data not shown). Similar results were observed with flow cyto- metric analysis. The proportion of $\mathrm{CD} 4^{+}$cells and $\mathrm{CD} 4^{+} \mathrm{CD} 25^{+}$ $\mathrm{FOXP}^{+} \mathrm{T}$ cells was measured in each group, as previously described [11].After OVA stimulation for 72 hours, the percentage of $\mathrm{CD}^{+}{ }^{+} \mathrm{CD} 25^{+} \mathrm{FOXP}^{+}{ }^{+} \mathrm{T}$ cells was $12.03 \%, 14.68 \%, 17.28 \%$, 

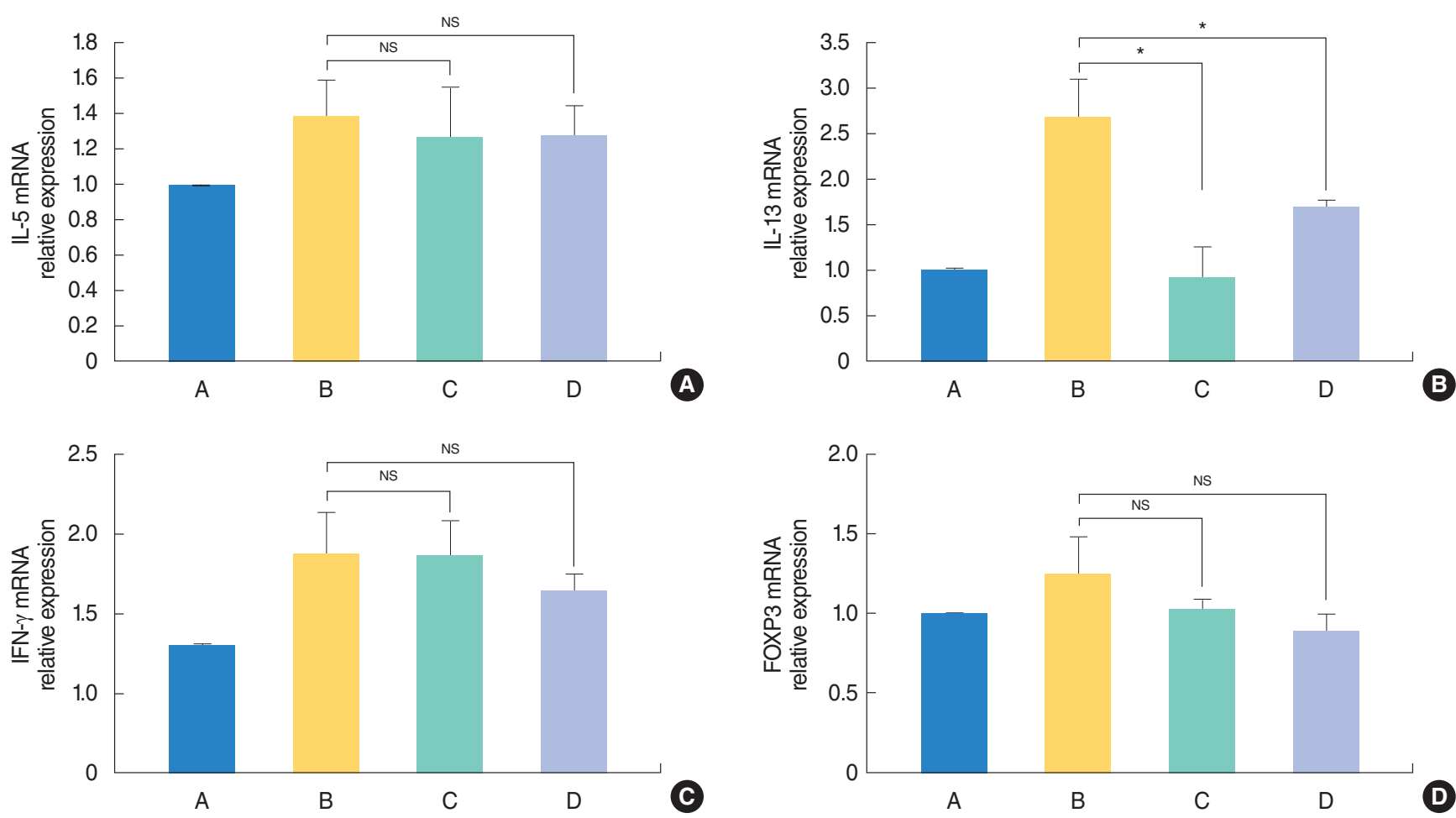

Fig. 4. Effect of Hizikia fusiformis on the nasal tissue cytokine expression. Local cytokine mRNA expression levels in the nasal mucosa were evaluated using real-time polymerase chain reaction after $\mathrm{H}$. fusiformis administration. Transcriptional activity of interleukin 13 (IL-13) decreased significantly (B); however, those of IL-5 (A), interferon $\gamma$ (IFN- $\gamma ; C$ ), and FOXP3 (D) did not significantly change in the groups $\mathrm{C}$ and D compared with the positive control group B. A, control group; B, allergic rhinitis group; C, H. fusiformis treatment group during nasal challenging period; D, H. fusiformis treatment group during general sensitization and nasal challenging period; NS, not significant. ${ }^{*} P<0.05$

and $10.17 \%$ for cells from group A, B, C, and D, respectively (Fig. 3B). For splenocytes without OVA stimulation, the percentage of $\mathrm{CD}^{+}{ }^{+} \mathrm{CD} 25^{+} \mathrm{FOXP}^{+} \mathrm{T}$ cells was $7.89 \%, 11.27 \%, 13.84 \%$, and $9.75 \%$ in group A, B, C, and D, respectively. As a result, the percentage of these cells was slightly higher in group $\mathrm{C}$ under both conditions. However, the elevation in the $\mathrm{CD} 4^{+} \mathrm{CD} 25^{+} \mathrm{FOXP} 3^{+} \mathrm{T}$ cell proportion was not observed in group $\mathrm{D}$ and there was significant difference between groups $\mathrm{C}$ and $\mathrm{D}(P<0.05)$ (Fig. 3B).

\section{Local effects of $H$. fusiformis evident from cytokine mRNA expression}

To evaluate the local antiallergic effect of $H$. fusiformis, the expression of mRNAs of various cytokines in the mouse nasal tissue was measured. An increase in the expression levels of IL-5, IL-13, IFN- $\gamma$, and FOXP3 mRNAs was observed in the nasal mucosa of group B mice, however, only the IL-13 levels significantly decreased for the samples from groups $\mathrm{C}$ and $\mathrm{D}(P<0.05)$ (Fig. 4).

\section{Reduced eosinophil/goblet cell counts in the nasal mucosa after $H$. fusiformis treatment}

Histopathologic evaluation results revealed the significant increase in eosinophil infiltration observed in samples from group B $(29.58 \pm 5.92 /$ high power field [HPF], $P<0.01)$ as compared with samples from group A $(1.25 \pm 0.35 / \mathrm{HPF})$. Eosinophil infil- tration showed significant decrease in samples from groups $\mathrm{C}$ and D (12.08 $\pm 2.90 / \mathrm{HPF}$ and 3.92 $\pm 1.24 / \mathrm{HPF}$, respectively; both $P<0.01$ ) (Fig. 5A, B). PAS staining results revealed the decrease in the number of goblet cells in samples from groups $\mathrm{C}$ and D with statistical significance $(P<0.05)$ (Fig. 5C, D).

\section{DISCUSSION}

H. fusiformis, widely consumed in Korea, China, and Japan, is a rich source of various soluble polysaccharides in the form of alginates, laminarins, fucoidans [5]. H. fusiformis exerts immunomodulatory effects $[1,3,7]$. Macrophages treated with $H$. fusiformis showed antioxidant and anti-inflammatory effects. $H$. fusiformis showed therapeutic effects against atopic dermatitis through the inactivation of nuclear factor of activated T cells [9]. Based on these previous study results, we suggest that $\mathrm{H}$. fusiformis may serve as an attractive option for the treatment of allergic diseases. In the present study, we evaluated the effects of H. fusiformis extract on nasal allergic inflammation and investigated the underlying mechanism. We found that the intraperitoneal administration of $H$. fusiformis extract resulted in a significant reduction in allergic nasal symptoms (rubbing and sneezing), Th2 cytokine production, and the number of eosinophils 

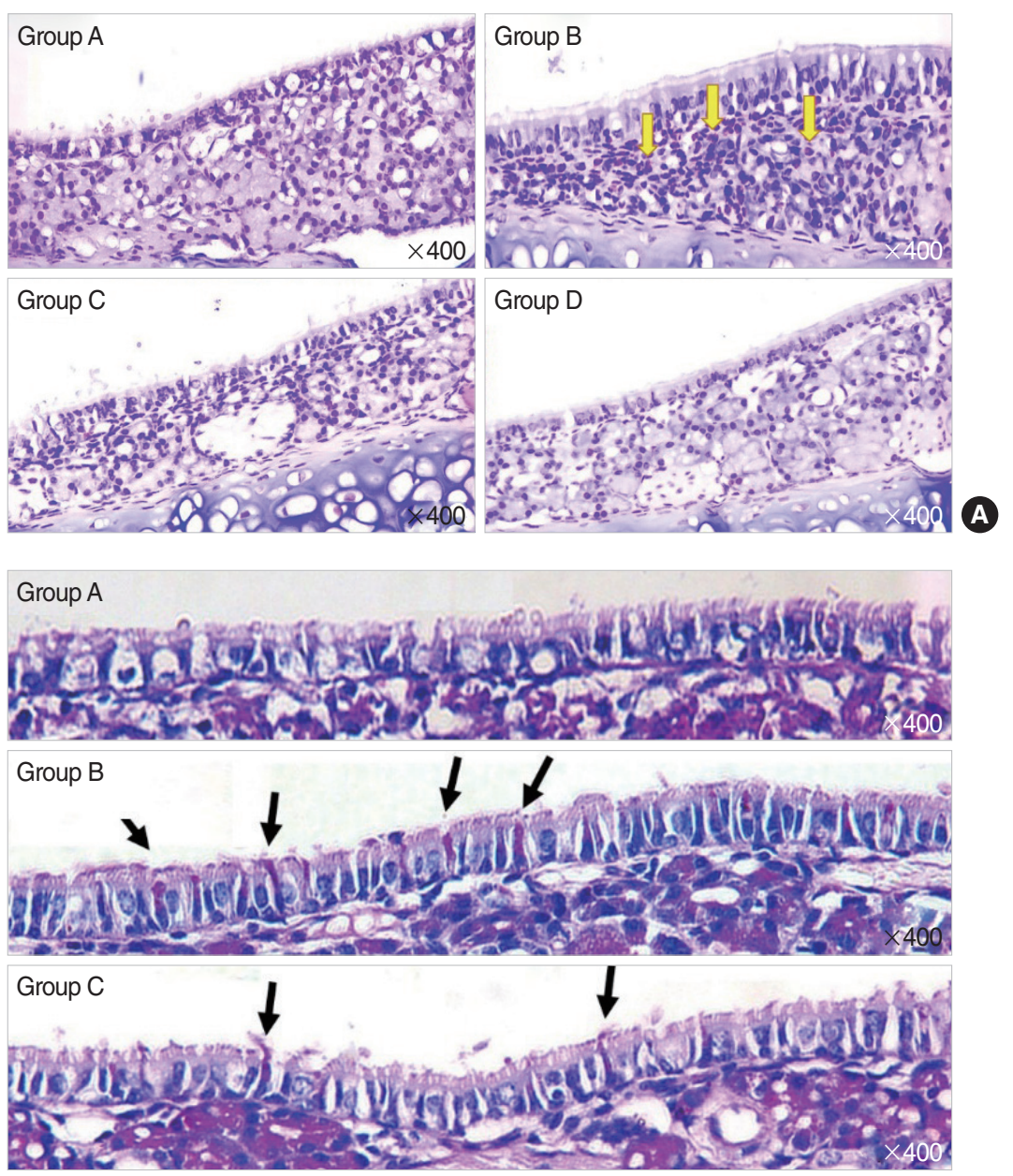

Group D

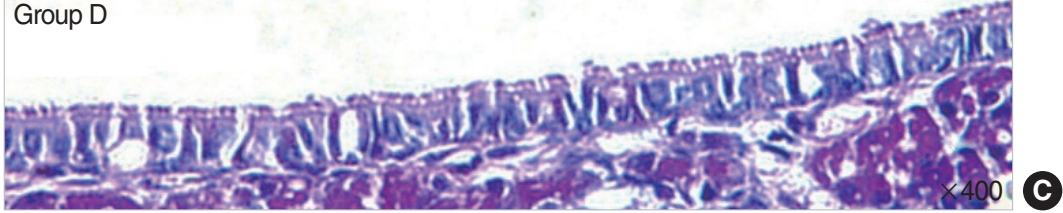

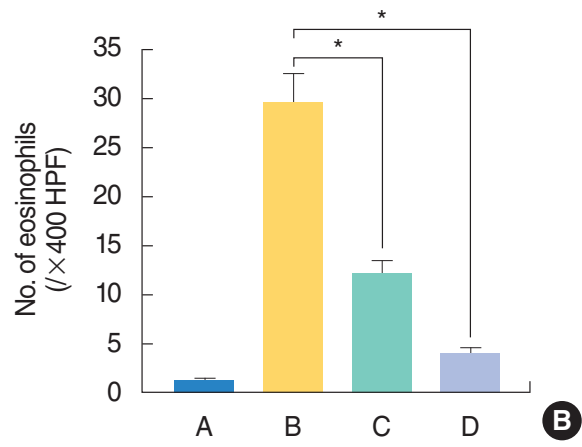

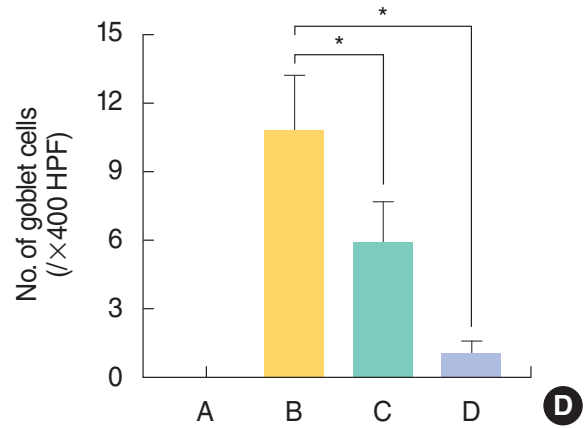

Fig. 5. Histopathological findings. (A, B) Eosinophil infiltration in the nasal mucosa. (C, D) Goblet cell hyperplasia in the nasal epithelium. (A) Subepithelial inflammatory cell infiltration including eosinophil was evident in group B and decreased in Hizikia fusiformis treatment groups C and D (Sirius red stain, $\times 400$; yellow arrows, eosinophils). (B) Eosinophil count was significantly reduced in treatment groups $\mathrm{C}$ and $\mathrm{D}$ compared with the positive group B. (C) Increased number of goblet cell in epithelial layer was identified in group B (black arrows, goblet cells). (D) Systemic administration of $H$. fusiformis suppress goblet cell hyperplasia in groups $\mathrm{C}$ and $\mathrm{D}$ compared with the positive control group $\mathrm{B}$ (Periodic acid-Schiff stain, $\times 400$ ). A, control group; $\mathrm{B}$, allergic rhinitis group; $\mathrm{C}, \mathrm{H}$. fusiformis treatment group during nasal challenging period; $\mathrm{D}, \mathrm{H}$. fusiformis treatment group during general sensitization and nasal challenging period; HPF, high power field. ${ }^{*} P<0.05$.

infiltration, suggesting that $H$. fusiformis may potentially control allergic rhinitis symptoms in mice.

The imbalance between Th2 and Th1 polarization results in allergic phenotype features such as asthma, allergic rhinitis, and atopic dermatitis [12-14]. In our experiment, we used aTh2-driven allergen and adjuvant (OVA and aluminum hydroxide gel) as positive control. Mice treated with $H$. fusiformis extract (groups $\mathrm{C}$ and $\mathrm{D}$ ) demonstrated decreased response not only in terms of OVA-specific IgE Abs but in the form of $\operatorname{IgG}_{22} / \operatorname{IgG}_{1}$ Abs. $\operatorname{IgG}_{2 a}$ and $\operatorname{IgG}_{1} \mathrm{Ab}$ isotypes are markers for Th1 and Th2 lymphocytes, respectively. Administration of $H$. fusiformis extract reduced the production of $\operatorname{IgG}_{2 a}$ and $\operatorname{IgG}_{1} A$ bs in groups $C$ and $D$ as compared with group B. In particular, compare to the $\mathrm{IgG}_{2 \mathrm{a}} \mathrm{Ab}$ being less than twice gap between groups $B$ and $D$, the level of $\operatorname{IgG}_{1} A b$ of the group $\mathrm{D}$ was as lower as one-fourth that of group $\mathrm{B}$.

Moreover, Th2 cytokine such as IL-4, IL-5 and IL-13 are important mediator in the pathogenesis of allergic rhinitis. In our study, the mRNA expression of IL-13 was significantly decreased in H. fusiformis-treated groups C and D. IL-13 is responsible for maintaining late-phase allergic inflammation and asso- 
ciated with mucous production by promoting the hyperplasia of goblet cells in the epithelium secreting the mucopolysaccharide (mucin) into the airway $[15,16]$. Treatment of $H$. fusiformis significantly suppressed the IL-13 production resulting in significant decrease of the number of mucous-producing goblet cells (Fig. 5C, D). As for IL-4, another important Th2 cytokine for IgE production, reduced systemic IL-4 production from splenocyte culture consistent with the decreased production of OVA-specific serum IgE. Therefore, we summarized that one of the therapeutic effects of $H$. fusiformis is thought to be associated with the mechanism involving prevention of Th2-type immune response.

IgE-mediated allergic inflammation is initiated after the recognition of a foreign peptide by a naive $\mathrm{T}$ cell that is activated in the presence of IL-4. As a consequence, the activated T cell undergoes Th2-type differentiation. Previous studies evaluating the role of macrophages in allergic rhinitis mice intranasally sensitized with cedar pollen have shown that macrophages are essential not only for IL-4 or immunoglobulin production but also for class switching of immunoglobulin in lymphocytes [17]. This result clarifies the role of macrophages that serve as a connecter between the innate and adaptive immunity in murine allergic rhinitis by acting as antigen-presenting effectors. We have previously shown that the treatment of a macrophage cell line (RAW 264.7) with a viscozyme fraction of $H$. fusiformis resulted in efficient antioxidant and anti-inflammatory effects. Among several mediators released from macrophages, TNF- $\alpha$ production increased by lipopolysaccharides treatment ameliorated by the $H$. fusiformis treatment (unpublished data). TNF- $\alpha$ is released from activated phagocytes [18]. Therefore, this fraction was thought to exhibit any potential in allergic disease, and hence, used in the present study. Several lines of study relating TNF- $\alpha$ supported its antiallergic effect in murine asthma or murine allergic rhinitis model. One study demonstrated that anti-TNF- $\alpha$ antibody could suppress the level of eotaxin in asthma model [19]. In another study using TNF- $\alpha$ knock out mice, it was proven that TNF- $\alpha$ was necessary for OVA-specific IgE production and for Th2 cytokines/chemokines [20]. Other study with TNF- $\alpha$ inhibitor showed the decreased expression of adhesion molecule, thus inhibiting of migration of effector cell in murine model of allergic rhinitis [21]. However, there are also some contrary results that knock out the TNF- $\alpha$ would increase the airway-hypersensitiveness, suggesting the pro-inflammatory effect of TNF- $\alpha$, thus more evidences are needed for clarification [22].

In our study, to clarify the mechanism involved in antiallergic effect of $H$. fusiformis, we administered the extract in two treatment methods, multiple injection before only local sensitization period (group C) and multiple injections before both general and local sensitization period (group D) and compared the efficacy using several parameters. All of the aforementioned effects were evident in the mice from group D that were treated with $H$. fusiformis extract during sensitization as well as nasal challenge pe- riod than in the mice from group $\mathrm{C}$ that were treated only during the nasal challenge period. Mice from group D showed a significant decrease in the production of OVA-specific IgE, $\operatorname{IgG}_{2 a}$, and $\mathrm{IgG}_{1} \mathrm{Abs}$, consistent with the least eosinophil infiltration and allergic symptom scores reported for this group. Mice from group C showed a similar improving tendency in many parameters like mice from group D, however, they failed to show statistical significance except symptom scores, OVA-specific IgE, IL-13 mRNA expression and histologic findings. Considering the abolishment of TNF- $\alpha$ in group D (Fig. 3A), we assumed that TNF- $\alpha$ could be one of the answer why mice from group $C$ had a limited antiallergic effect, compared to mice from group D. It might be not enough for alleviating all allergic inflammation by administration the $H$. fusiformis only in nasal challenging period.

The other difference noticed between the groups $\mathrm{C}$ and $\mathrm{D}$ is the Tregs. FOXP3 is considered as a regulator of Tregs. In general, the expression of Tregs is upregulated in response to immune responses for the alleviation of inflammation. Failure to maintain immune tolerance against environmental factors results in allergic reactions such as allergic rhinitis, allergic asthma, and atopic dermatitis. Thus, Tregs are essential for the maintenance of immune tolerance through the prevention of Th2 induction and Th2 cytokine release [23]. Several studies have supported the relationship between Tregs and allergic diseases. In patients with allergic rhinitis and uncontrolled asthma, the in vitro function of $\mathrm{FOXP3}^{+}$Tregs was decreased, and Tregs from patients with asthma showed impaired regulation of chemokine signaling pathway [24-32]. In our study, evaluation of the Treg population revealed that the basal concentration of IL-10 cytokine without OVA stimulation was around $100 \mathrm{pg} / \mathrm{mL}$ in the mice from group $\mathrm{C}$, which was significantly increased compared with positive control group $\mathrm{B}(P<0.05)$, and this concentration increase by three times following OVA stimulation. However, the level of IL-10 was unchanged in the mice from group D following OVA stimulation and remained the lowest concentration with statistical significance $(P<0.05)$ (Fig. 3A). The different methods of administration of $H$. fusiformis might elicit a different anti-inflammatory response. In group $\mathrm{C}$, therefore, to suppress allergic inflammation in response to OVA sensitization, $H$. fusiformis extract induces Treg expression (according to flow cytometric analysis) and elevates the levels of IL-10 cytokine (according to ELISA results). In the contrary, the number of $\mathrm{CD} 4{ }^{+} \mathrm{CD} 25^{+} \mathrm{FOXP}{ }^{+}$Tregs was significantly lower in group D than in group C (Fig. 3B). These contrary results between groups $\mathrm{C}$ and $\mathrm{D}$ in activation of the Tregs system may be explained like that the administration of $H$. fusiformis during sensitization period may lighten the allergenicity of OVA with alum adjuvant, which may not sufficiently activate the Treg immune system at the initial stage. Taken all together, we suggest that $H$. fusiformis could exert antiallergic effects by decreasing the production of IgE Abs and Th2 type inflammatory response, and/or induction the Tregs system. 
Our study has some limitations. First, $H$. fusiformis extract was given intraperitoneally in our study. The route of administration may have an effect on the local or systemic results. Thus, it is more appropriate to give the extract intranasally to see the local antiallergic effect. Second, the dose of $H$. fusiformis extract administered during general sensitization period was arbitrary determined within safety range based on the previous study. Thus, the accurate effectiveness of $H$. fusiformis could be demonstrated with several different doses of it. Third, the character of Treg cells discussed here is likely to correlate with the inducible Treg cell [33], the accurate subpopulation study is needed for draw a conclusion.

To the best of our knowledge, this is the first study indicating the effect of $H$. fusiformis in a murine model of allergic rhinitis. $H$. fusiformis extract significantly improved nasal symptom score, OVA-specific IgE production, Th2 cytokine release and histopathologic inflammation in OVA induced murine allergic rhinitis model. Thus, the therapeutic effects of $H$. fusiformis suggestive of the feasibility of this extract for therapeutic applications in allergic rhinitis.

\section{CONFLICT OF INTEREST}

No potential conflict of interest relevant to this article was reported.

\section{ACKNOWLEDGMENTS}

This research was financially supported by the Ministry of Trade, Industry and Energy (MOTIE) and Korea Institute for Advancement of Technology (KIAT) through the Research and Development for Regional Industry (No. R0006329) and by Basic Science Research Program through the National Research Foundation of Korea (NRF) funded by the Ministry of Science, ICT \& Future Planning (NRF-2017R1C1B5017429), Republic of Korea.

\section{ORCID}

Yu-Lian Zhang https://orcid.org/0000-0002-4079-8155

Jieun Lee https://orcid.org/0000-0001-9043-140X

\section{REFERENCES}

1. Shan BE, Yoshida Y, Kuroda E, Yamashita U. Immunomodulating activity of seaweed extract on human lymphocytes in vitro. Int J Immunopharmacol. 1999 Jan;21(1):59-70.

2. Huh GW, Lee DY, In SJ, Lee DG, Park SY, Yi TH, et al. Fucosterols from Hizikia fusiformis and their proliferation activities on osteosar- coma-derived cell MG63. J Korean Soc Appl Biol Chem. 2012 Aug; 55(4):551-55.

3. Yang EJ, Moon JY, Kim MJ, Kim DS, Kim CS, LeeWJ, et al. Inhibitory effect of Jeju endemic seaweeds on the production of pro-inflammatory mediators in mouse macrophage cell line RAW 264.7. J Zhejiang Univ Sci B. 2010 May;11(5):315-22.

4. Kang CH, Kang SH, Boo SH, Pak SY, Choi YH, Moon DO, et al. Ethyl alcohol extract of Hizikia fusiforme induces caspase-dependent apoptosis in human leukemia U937 cells by generation of reactive oxygen species. Trop J Pharm Res. 2011 Dec;10(6):739-46.

5. Wu M,WuY, Qu M, LiW, Yan X. Evaluation of antioxidant activities of water-soluble polysaccharides from brown alga Hizikia fusiformis. Int J Biol Macromol. 2013 May;56:28-33.

6. Choi EY, Hwang HJ, Kim IH, Nam TJ. Protective effects of a polysaccharide from Hizikia fusiformis against ethanol toxicity in rats. Food Chem Toxicol. 2009 Jan;47(1):134-9.

7. Sharma BR, Park CS, Ma SJ, Rhyu DY. Anti-inflammatory effects and mechanisms of Hizikia fusiformis via multicellular signaling pathways in lipopolysaccharide-induced RAW 264.7 cells. Pak J Pharm Sci. 2017 Jan;30(1):43-8.

8. Lee SG, Karadeniz F, Oh JH, Yu GH, Kong CS. Inhibitory effect of hizikia fusiformis solvent-partitioned fractions on invasion and MMP activity of HT1080 human fibrosarcoma cells. Prev Nutr Food Sci. 2017 Sep;22(3):184-90.

9. Lee KH, Kim HJ, Kim HB, Kim ST, Choi YR, Seo DW, et al. Hizikia fusiformis fractions successfully improve atopic dermatitis indices in anti-CD3-stimulated splenocytes and 2,4-dinitrochlorobenzene-treated BALB/c mice. J Pharm Pharmacol. 2014 Mar;66(3):466-76.

10. LeeTH.A pharmaceutical composition for alleviation, prevention or treatment of metabolic bone disease comprising an extract of fermented hizikia fusiforme and health functional food comprising the same [Internet]. Seoul: Korean Intellectual Property Office; 2013 [cited 2018 Nov 27]. Available from: https://patentimages.storage. googleapis.com/b6/ea/75/3087433255b3d2/KR101305621B1.pdf.

11. Lee JE, Zhang YL, Han DH, Kim DY, Rhee CS. Antiallergic function of KR62980, a peroxisome proliferator-activated receptor- $\gamma$ agonist, in a mouse allergic rhinitis model.Allergy Asthma Immunol Res. 2015 May;7(3):256-64.

12. Saito H, Matsumoto K, Denburg AE, Crawford L, Ellis R, Inman MD, et al. Pathogenesis of murine experimental allergic rhinitis: a study of local and systemic consequences of IL-5 deficiency. J Immunol. 2002 Mar;168(6):3017-23.

13. Hellings PW, Hessel EM, Van Den Oord JJ, Kasran A, Van Hecke P, Ceuppens JL. Eosinophilic rhinitis accompanies the development of lower airway inflammation and hyper-reactivity in sensitized mice exposed to aerosolized allergen. Clin Exp Allergy. 2001 May;31(5): 782-90.

14. Hussain I, Randolph D, Brody SL, Song SK, Hsu A, Kahn AM, et al. Induction, distribution and modulation of upper airway allergic inflammation in mice. Clin Exp Allergy. 2001 Jul;31(7):1048-59.

15. Wills-Karp M, Luyimbazi J, Xu X, Schofield B, Neben TY, Karp CL, et al. Interleukin-13: central mediator of allergic asthma. Science. 1998 Dec;282(5397):2258-61.

16. Eifan AO, Durham SR. Pathogenesis of rhinitis. Clin Exp Allergy. 2016 Sep;46(9):1139-51.

17. Hirano M, Ogita-Nakanishi H, MiyachiW, Hannya N, Yamamoto-Kimoto Y, Sakurai K, et al. Essential role of macrophages in the initiation of allergic rhinitis in mice sensitized intranasally once with cedar pollen: regulation of class switching of immunoglobulin in B cells by controlling interleukin-4 production in T cells of submandibular lymph nodes. Microbiol Immunol. 2012 Jun;56(6):392-405.

18. Artis D, Humphreys NE, Bancroft AJ, Rothwell NJ, Potten CS, Grencis RK. Tumor necrosis factor alpha is a critical component of interleukin 13-mediated protective T helper cell type 2 responses during 
helminth infection. J Exp Med. 1999 Oct;190(7):953-62.

19. Kim J, McKinley L, Natarajan S, Bolgos GL, Siddiqui J, Copeland S, et al. Anti-tumor necrosis factor-alpha antibody treatment reduces pulmonary inflammation and methacholine hyper-responsiveness in a murine asthma model induced by house dust. Clin Exp Allergy. 2006 Jan;36(1):122-32.

20. Iwasaki M, Saito K, Takemura M, Sekikawa K, Fujii H, Yamada Y, et al. TNF-alpha contributes to the development of allergic rhinitis in mice. J Allergy Clin Immunol. 2003 Jul;112(1):134-40.

21. Mo JH, Kang EK, Quan SH, Rhee CS, Lee CH, Kim DY. Anti-tumor necrosis factor-alpha treatment reduces allergic responses in an allergic rhinitis mouse model.Allergy. 2011 Feb;66(2):279-86.

22. Kanehiro A, Lahn M, Makela MJ, Dakhama A, Fujita M, Joetham A, et al. Tumor necrosis factor-alpha negatively regulates airway hyperresponsiveness through gamma-delta T cells. Am J Respir Crit Care Med. 2001 Dec;164(12):2229-38.

23. Pellerin L, Jenks JA, Begin P, Bacchetta R, Nadeau KC. RegulatoryT cells and their roles in immune dysregulation and allergy. Immunol Res. 2014 May;58(2-3):358-68.

24. Grindebacke H,Wing K, Andersson AC, Suri-Payer E, Rak S, Rudin A. Defective suppression of Th2 cytokines by CD4CD25 regulatory T cells in birch allergics during birch pollen season. Clin Exp Allergy. 2004 Sep;34(9):1364-72.

25. Ling EM, Smith T, Nguyen XD, Pridgeon C, Dallman M, Arbery J, et al. Relation of CD4+CD25+ regulatory T-cell suppression of allergendriven T-cell activation to atopic status and expression of allergic disease. Lancet. 2004 Feb;363(9409):608-15.
26. Kinoshita T, Baatjes A, Smith SG, Dua B, Watson R, Kawayama T, et al. Natural regulatory $\mathrm{T}$ cells in isolated early responders compared with dual responders with allergic asthma. J Allergy Clin Immunol. 2014 Mar;133(3):696-703.

27. Lee JH, Yu HH, Wang LC, Yang YH, Lin YT, Chiang BL. The levels of $\mathrm{CD} 4+\mathrm{CD} 25+$ regulatory $\mathrm{T}$ cells in paediatric patients with allergic rhinitis and bronchial asthma. Clin Exp Immunol. 2007 Apr;148(1): 53-63.

28. Lin YL, Shieh CC, Wang JY. The functional insufficiency of human CD4+CD25 high T-regulatory cells in allergic asthma is subjected to TNF-alpha modulation. Allergy. 2008 Jan;63(1):67-74.

29. Moniuszko M, Kowal K, Zukowski S, Dabrowska M, Bodzenta-Lukaszyk A. Frequencies of circulating CD4+CD25+CD127low cells in atopics are altered by bronchial allergen challenge. Eur J Clin Invest. 2008 Mar;38(3):201-4.

30. Hartl D, Koller B, Mehlhorn AT, Reinhardt D, NicolaiT, Schendel DJ, et al. Quantitative and functional impairment of pulmonary CD4+ CD25hi regulatory T cells in pediatric asthma. J Allergy Clin Immunol. 2007 May;119(5):1258-66.

31. Thunberg S, Gafvelin G, Nord M, Gronneberg R, Grunewald J, Eklund A, et al. Allergen provocation increases TH2-cytokines and FOXP3 expression in the asthmatic lung. Allergy. 2010 Mar;65(3):311-8.

32. Smyth LJ, Eustace A, Kolsum U, Blaikely J, Singh D. Increased airwayT regulatory cells in asthmatic subjects. Chest. 2010 Oct;138(4): 905-12.

33. Noval Rivas M, Chatila TA. Regulatory T cells in allergic diseases. J Allergy Clin Immunol. 2016 Sep;138(3):639-52. 